\section{Light-emitting Diodes as a Radiation Source for Plants}

\author{
R.J. Bula, R.C. Morrow, T.W. Tibbitts, and D.J. Barta \\ Wisconsin Center for Space Automation and Robotics and Department of \\ Horticulture, University of Wisconsin-Madison, Madison, WI 53706
}

\author{
R.W. Ignatius and T.S. Martin \\ Automated Agriculture Associates, Dodgeville, WI 53533
}

Additional index words. Lactuca sativa, lettuce, growth, dry weight, controlled environments

\begin{abstract}
Development of a more effective radiation source for use in plant-growing facilities would be of significant benefit for both research and commercial crop production applications. An array of light-emitting diodes (LEDs) that produce red radiation, supplemented with a photosynthetic photon flux (PPF) of $30 \mu \mathrm{mol} \cdot \mathrm{s}^{-1} \cdot \mathrm{m}^{-2}$ in the 400- to 500-nm spectral range from blue fluorescent lamps, was used effectively as a radiation source for growing plants. Growth of lettuce (Lactuca sativa L. 'Grand Rapids') plants maintained under the LED irradiation system at a total PPF of 325 $\mu \mathrm{mol} \cdot \mathrm{s}^{-1} \cdot \mathrm{m}^{-2}$ for 21 days was equivalent to that reported in the literature for plants grown for the same time under cool-white fluorescent and incandescent radiation sources. Characteristics of the plants, such as leaf shape, color, and texture, were not different from those found with plants grown under cool-white fluorescent lamps. Estimations of the electrical energy conversion efficiency of a LED system for plant irradiation suggest that it may be as much as twice that published for fluorescent systems.
\end{abstract}

Controlled-environment chambers are used extensively to study the environmental physiology of plants (Langhans, 1978; Tibbitts and Kozlowski, 1979). Although plant growth rooms have been used for starting plant materials on a commercial scale for some time, more recently, controlled-environment facilities have been developed for production of commercial crops (Davis, 1985). For photoautotrophic plants, the segment of radiant energy defined as photosynthetically active radiation (PAR), 400 to $700 \mathrm{~nm}$, is the major environmental factor controlling their growth. The spectral output of the radiation source must meet the plant's requirements for photosynthesis and photomorphogenic development.

The most commonly used radiation sources in plant-growing facilities are fluorescent, metal halide, high-pressure sodium, and incandescent lamps. These commercially available lamps were developed for human lighting applications. Since the photoreceptors of plants differ from those of humans, light sources presently used in plant-growing

Received for publication 5 Mar. 1990. We gratefully acknowledge the assistance of J.C. Vignali and M.E. Hocnecke in conducting this research. This study was supported in part by NASA under grant NAG-W975. The cost of publishing this paper was defrayed in part by the payment of page charges. Under postal regulations, this paper therefore must be hereby marked advertisement solely to indicate this fact. facilities have various limitations and, consequently, are not an optimum radiation source for plants. Different lamp types provide varying proportions of radiant flux in the PAR and infrared spectral regions (Bubenheim et al., 1988). The spectral balance of the source not only affects the photosynthetic efficiency, but also has a significant impact on the maintenance of the thermal balance in the enclosed chamber and on the plants in the chamber.

A radiation source with improved electrical efficiency and one that engenders improved photosynthetic efficiency would be of significant benefit for both research and commercial crop production applications. A plant irradiation system based on light-emitting diodes (LEDs) has been described (Ignatius et al., 1988). The objectives of this research were to determine some of the unique characteristics of various red radiation-emitting LEDs and to evaluate their potential as a radiation source for plant growth by comparing the growth of lettuce plants under an LED array to growth responses reported in the literature.

Characteristics of LED lamps. Lightemitting diodes based on a gallium-aluminum-arsenide substrate (GaAIAs), also referred to as AIGaAs, are available with peak emissions ranging from 630 to $940 \mathrm{~nm}$. The most commonly available GaAIAs LEDs emit radiation in the red region of the spectrum that coincides with the maximum absorption of chlorophyll. The spectral energy distribution of one of the commercially available LEDs is shown in Fig. 1. Such LEDs have a peak emission at $\approx 660 \mathrm{~nm}$, with a typical spectral band width of $25 \mathrm{~nm}$, at half power. The wavelength of the peak emission is controlled by several factors, including the chemical composition of the LED chip (a chip is defined as the length, width, and thickness of the GaAIAs material used in the LED), current level used to power the LED, and ambient temperature. The most significant of these is the chemical composition of the chip, as determined by the ratio of aluminum to gallium in the alloy that makes up the layers of the GaAIAs system (Steranka et al., 1988).

The photosynthetic photon flux (PPF) of various commercial and experimental GaAIAs LEDs, measured with a LI-COR LI190SA quantum sensor (LI-COR, Lincoln, $\mathrm{Neb}$.), was found to vary greatly. An output variation from 70 to $540 \mu \mathrm{mol} \cdot \mathrm{s}^{-1} \cdot \mathrm{m}^{-2}$ was observed among individual LEDs from different lots when measurements were taken 1 $\mathrm{cm}$ from the tip of the LED. All the LEDs were compared at a current of $50 \mathrm{~mA}$, which equates to $\approx 100 \mathrm{~mW}$ for each LED, depending on the resistance of the specific LED.

A major factor related to the PPF output was whether the LED chip had a transparent (TS) or absorbing (AS) substrate. The average PPF output of LEDs with a TS substrate varied from 332 to $596 \mu \mathrm{mol} \cdot \mathrm{s}^{-1} \cdot \mathrm{m}^{-2}$, whereas the average output of the LEDs with an AS substrate varied from 120 to 425

Table 1. Characteristics of 21-day-old 'Grand Rapids' lettuce plants grown under a LED plant irradiation system and under cool-white fluorescent (CWF) plus incandescent (Inc) lamps.

\begin{tabular}{lcc}
\hline \hline Plant characteristic & $\begin{array}{c}\text { LED system } \\
(\text { mean } \pm \mathrm{SE})\end{array}$ & CWF + Inc lamps \\
\hline \hline Fresh weight $(\mathrm{g})$ & $19.0 \pm 2.76$ & 16.7 \\
Dry weight $(\mathrm{g})$ & $1.11 \pm 0.16$ & 0.97 \\
Stem length $(\mathrm{mm})$ & $9.3 \pm 0.63$ & 10.2 \\
Number of nodes & & 9.6 \\
$\quad$ with leaves $>1 \mathrm{~cm}$ long & $11.0 \pm 1.73$ & 123.3 \\
Length of fifth leaf $(\mathrm{mm})$ & $111.7 \pm 6.60$ & 117.5 \\
Width of fifth leaf $(\mathrm{mm})$ & $117.7 \pm 11.50$ & \\
\hline
\end{tabular}

${ }^{2}$ Data are mean values of two plants from each of three separate growth periods.

${ }^{y}$ Data from Hammer et al. (1978), SE values not available. 


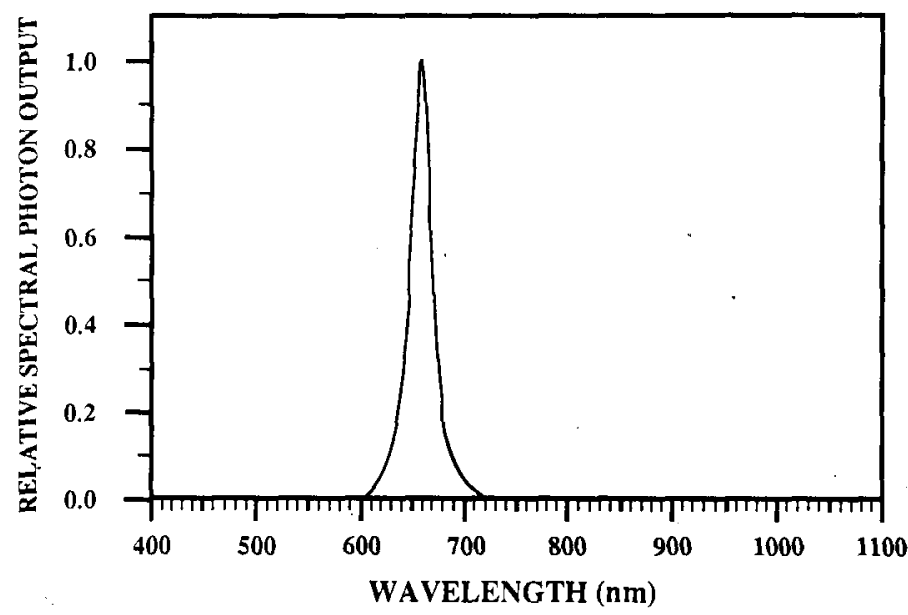

Fig. 1. Spectral energy distribution of a gallium-aluminum-arsenide (GaAIAs) light-emitting diode (LED) having a peak emission at $\approx 660 \mathrm{~nm}$.

$\mu \mathrm{mol} \cdot \mathrm{s}^{-1} \cdot \mathrm{m}^{-2}$, Transparent-substrate, double heterostructure chips derived from slowcooling, liquid-phase epitaxial-grown wafers have been reported to have significantly greater output than other GaAIAs LEDs (Cook et al., 1987).

Other LED characteristics that can affect the measured PPF include the angle of dispersion, chip size, and variations inherent in the production of semiconductors. The angle of dispersion is defined as the angular output of the photons emitted by the LED. Being essentially a cube, the chip emits photons from its six surfaces. In mounting the chip, a reflective surface is used to direct the photons from the chip surfaces in an on-axis direction away from the wire leads. Manufacturers most commonly have developed devices that have angles of dispersion of $8^{\circ}$ to $20^{\circ}$. Evaluations will be needed to determine the optimum angle of photon dispersion of LEDs for use as a plant growth radiation source. The observed differences in output of some of the LEDs evaluated may reflect differences in chip size. Most LEDs contain a chip that is about a $200-\mu \mathrm{m}$ cube. Within limits, devices having larger chips would have greater output than those with smaller chips. However, manufacturers generally do not specify the chip size used in an LED.

Significant differences in PPF output were observed among individual LEDs within a specific lot. The maximum output of individual LEDs within a single lot varied as much as $\pm 30 \%$ of the average output. Some manufacturers measure the output of the LEDs within each lot produced and distribute selections from these lots as separate catalog item devices having different levels of brightness. The output of such separate catalog items, indicating increasing brightness, from one manufacturer averaged 330, 483, and $496 \mu \mathrm{mol} \cdot \mathrm{s}^{-1} \cdot \mathrm{m}^{-2}$. However, within a selected catalog item that represented such selected devices, the output of individual LEDs varied as much as $\pm 70 \mu \mathrm{mol} \cdot \mathrm{s}^{-1} \cdot \mathrm{m}^{-2}$.

Plant growth evaluations. An array of TStype LEDs with a lens diameter of $5.0 \mathrm{~mm}$ and a dispersion angle of $8^{\circ}$ was fabricated for evaluation of their usefulness as a plant growth irradiation source. The LEDs were mounted on a clear polycarbonate board in rows spaced $0.75 \mathrm{~cm}$ apart and $1.5 \mathrm{~cm}$ on center within the rows. Placement of the LEDs was staggered to form a diagonal arrangement of the LEDs, The array contained 540 LEDs and was $19 \times 34.75 \mathrm{~cm}$ (45 rows with 12 LEDs per row and a $0.5-\mathrm{cm}$ border). The radiation output of the GaAIAs LED array was supplemented with blue fluorescent (BF) lamps (F20 T12/246) to provide a PPF of 30 $\mu \mathrm{mol} \cdot \mathrm{s}^{-1} \cdot \mathrm{m}^{-2}$ in the 400 -to 500 -nm spectral region at the plant canopy level. The fluorescent lamps were located above the LED array. The clear plastic board on which the LEDs were mounted allowed the output of the blue fluorescent lamps to be transmitted to the plant canopy.

'Grand Rapids' lettuce was grown from seed using the procedures described in the "base-line" growth studies (Hammer et al., 1978). The plant growth experiments were conducted in the Univ. of Wisconsin Biotron. The total PPF (LED plus BF) was maintained at $325 \pm 10 \mu \mathrm{mol} \cdot \mathrm{s}^{-1} \cdot \mathrm{m}^{-2}$ at the top of the plant canopy $(\approx 10 \mathrm{~cm}$ below the LED array) and a 16-h photoperiod. Air was at $25 \pm 1 \mathrm{C}$ during the light period and at $20 \pm 1 \mathrm{C}$ during the dark period. Relative humidity was maintained at $70 \% \pm 5 \%$. Carbon dioxide concentration of the air was maintained at ambient levels of $\approx 350 \mathrm{ppm}$ by continuously mixing growth room air with fresh air.

Plant characteristics of fresh and dry weights of the aerial portion, leaf length and width, stem length, and number of nodes were determined at the end of 21 days of growth. The plant data represent averages of two plants from each of three separate growth periods.

Characteristics of the lettuce plants grown under the LED array are given in Table 1. For comparison purposes, the mean values for 21-day-old lettuce plants grown under cool-white fluorescent and incandescent lamps, as reported by Hammer et al. (1978), also are included. All characteristics of the lettuce plants grown under the LED irradia- tion system for 21 days were equivalent to the values reported by Hammer et al. (1978) for plants grown for the same duration at 325 $\mu \mathrm{mol} \cdot \mathrm{s}^{-1} \cdot \mathrm{m}^{-2}$ and similar temperature and humidity conditions. Qualitative or visual characteristics of the plants, such as leaf shape, color, and texture, were not different from those expected of lettuce plants at this stage of development.

The data presented in Table 1 are based on limited evaluations, and consequently, it is not possible to conclude with certainty that plant growth under an LED radiation system is greater than under a cool-white fluorescent system at equal photon levels. Additional studies are needed to adequately address such comparisons.

An important advantage of the LED radiation system is that the peak spectral output of the LEDs coincides closely with the red absorption peak of chlorophyll and the reported wavelengths of maximum photosynthetic efficiency (McCree, 1972). Thus, a greater photosynthetic efficiency can be expected from radiation emitted by these LEDs than from lamps generating radiation spread across the 400- to 700-nm spectral region. Sager et al. (1982) reported that plant dry weight accumulation was greater when the plants were grown under red fluorescent lamps at similar PPF levels, compared to those grown under blue or daylight fluorescent lamps, and related this to the greater photosynthetic efficiency of the photons from the red fluorescent lamps.

In addition, LEDs are fabricated with an internal reflector to direct the emitted radiation out of the tip of the device in a narrow cone. This contrasts with the problems inherent in the use of fluorescent lamps, where radiation is emitted in all directions and a significant portion of the photons cannot be effectively reflected to the plants when lamps are mounted close together, as is the situation in plant growth facilities.

This study was not designed to compare the electrical conversion efficiency of LEDs to cool-white fluorescent lamps as a plant irradiation source; however, some approximations of this important consideration can be made. The LED array used in this research required $\approx 2.5 \mathrm{~W} \cdot \mu \mathrm{mol}^{-1} \cdot \mathrm{s}^{-1}$. Definitive measurements of installed fluorescent light systems in controlled-environment rooms have not been published; however, values reported by Tibbitts et al. (1976) for several plant growth facilities using fluorescent lamps as the radiation source ranged from $\approx 4.1$ to $6.9 \mathrm{~W} \cdot \mu \mathrm{mol}^{-1} \cdot \mathrm{s}^{-1}$. These comparisons suggest that the electrical energy conversion efficiency of the LED system used for plant irradiation in this study was in the range of twice that of fluorescent systems.

As technology improves the characteristics and photon output of LEDs, the performance of LEDs as a plant lighting source can likewise be expected to improve. The characteristics that need to be studied specifically include the following: the effect of peak wavelength of the irradiance emitted by the LED on plant productivity, the angle of dispersion of the photons to provide uniform 
irradiance on the plant growing surface, and definition of the factors that affect degradation of the output of these devices with respect to aging and environmental exposure (maintenance of PPF output over time). It is reasonable to expect that significant improvements in electrical power conversion efficiency of LEDs for use in a plant lighting source will be realized in the future.

At present, LEDs that emit in the blue spectral region are expensive and emit low photon levels. Improvements will need to be made in LEDs that emit radiation in the blue region of the spectrum before a total LED plant irradiation system is available, except for very specialized applications, such as research in space.

\section{Literature Cited}

Bubenheim, D.L., B. Bugbee, and F.B. Salis- bury. 1988. Radiation in controlled environments: Influence of lamp type and filter material. J. Amer. Soc. Hort. Sci. 113:468-474.

Cook, L. W., M.D. Camras, S.L. Rudaz, and F.M Steranka. 1987. High efficiency $650 \mathrm{~nm}$ aluminum gallium arsenide light emitting diodes. Proc. Intl. Symp. GaAs and Related Compounds, Heraklion, Greece, 1987. Inst. Phys. Conf. Ser. no. 91:777-780.

Davis, N. 1985. Controlled environment agriculture-Past, present, and future. Food Technol. 39:124-126, 134.

Hammer, P.A., T.W. Tibbitts, R.W. Langhans, and J.C. McFarlane. 1978. Baseline growth studies of 'Grand Rapids' lettuce in controlled environments. J. Amer. Soc. Hort. Sci. 103:649655.

Ignatius, R.W., T.S. Martin, R.J. Bula, R.C. Morrow. and T.W. Tibbitts. 1988. Method and apparatus for irradiation of plants using optoe. lectronic devices. U.S. Patent Application 07/ 283,245 .

Langhans, R.W. (ed.). 1978. A growth chamber manual. Environmental control for plants. Comstock Publishing Assoc., Ithaca, N.Y.

McCree, K.J. 1972. The action spectrum, absorptance and quantum yield of photosynthesis in crop plants. Agr. Meteorol. 9:191-216.

Sager, J.C., J.L. Edwards, and W.H. Klein. 1982. Light energy utilization efficiency for photosynthesis. Trans. Amer. Soc. Agr. Eng. 25:17371746.

Steranka, F.M., D.C. DeFevere, M.D. Camras, Chin-Wang Tu, D.K. McElfresh, S.L. Rudaz, L.W. Cook, and W.L. Snyder. 1988. Red AIGaAs light-emitting diodes. Hewlett-Packard J. 39(4):84-88

Tibbitts, T,W. and T.T. Kozlowski (eds.). 1979, Controlled environment guidelines for plant research. Academic, New York.

Tibbitts, T.W., J.C. McFarlane, D.T. Krizek, W.L. Berry, P.A. Hammer, R.W. Langhans, R.A. Larson, and D.P. Ormrod. 1976. Radiation environment of growth chambers. J. Amer. Soc. Hort. Sci. 101:164-170. 